\title{
El Plan Estratégico Logístico: Una propuesta para una empresa sin ánimo de lucro
}

\author{
Ana Carolina Peinado Aldana ${ }^{1}$
}

\begin{abstract}
Resumen
El plan estratégico constituye una herramienta fundamental que permite dilucidar de manera organizada los pasos necesarios para llevar a cabo objetivos, este aspecto cobra más relevancia al momento de interrelacionarlo con la cadena logística de la empresa, fomentando resultados óptimos para la organización. Dicho contexto aplica también para las entidades sin ánimo de lucro, cuya naturaleza no impide eficiencia en sus procesos. El objetivo principal de este artículo es proponer un plan estratégico logístico para una empresa de Carácter social sin ánimo de lucro que se ajuste a la estrategia corporativa y potencialice el logro de sus objetivos organizacionales. Para tal fin, se realizó un diagnóstico de la empresa en cuanto a logística se refiere, caracterizando a la misma y evaluando su competitividad en integración y logística. Los resultados operativizan cuatro proyectos estratégicos identificados a partir del análisis de las fortalezas y debilidades empresariales y las oportunidades y amenazas del entorno que permitió plantear unas estrategias que buscan mejorar la competitividad de la empresa, mejorar su productividad y ofrecerle un mejor servicio al cliente.
\end{abstract}

\section{Palabras Claves}

Logística, Competitividad en integración, Caracterización, Estrategia Logística, Planeación Estratégica Logística.

\begin{abstract}
The strategic plan constitutes a fundamental tool that allows to elucidate in an organized way the necessary steps to carry out objectives, this aspect becomes more relevant at the moment of interrelating it with the logistic chain of the company, fomenting optimal results for the organization. This context also applies to non-profit entities, whose nature does not impede efficiency in their processes. The main objective of this article is to propose a strategic logistical plan for a non-profit social company that fits the corporate strategy and enhances the achievement of its organizational objectives. To this end, a diagnosis was made of the company in terms of logistics, characterizing it and assessing its competitiveness in integration and logistics. The results operationalize four strategic projects identified from the analysis of the strengths and weaknesses of the business and the opportunities and threats of the environment that allowed to propose strategies that seek to improve the competitiveness of the company, improve its productivity and provide better customer service.
\end{abstract}

\section{Keywords}

Logistics, Competitiveness in integration, Characterization, Logistics Strategy, Strategic Logistics Planning

Fecha de recepción: 15 de Noviembre de 2018, Fecha de evaluación: 9 de Enero de 2019, Fecha de aceptación: 17 de Febrero de 2019

1. Magister en Gestión Logística. Pregrado en Ingeniería Electrónica. Vinculada a la Escuela militar de aviación marco fidel Suarez EMAVI. Correo electrónico: apeinado1@hotmail.com 


\section{Introducción}

La logística es un proceso integrado en las organizaciones, que su correcta gestión de la mano de los diferentes flujos (capital, bienes y servicios, información, personas) inciden el nivel competitivo de las organizaciones (Peinado, 2018). Del mismo modo (Álzate y Pérez, 2018) afirman que la logística es un proceso integrador que impacta en el desempeño, la competitividad de la organización y en la satisfacción de los clientes. Por otra parte, la Empresa de carácter social sin ánimo de lucro "es una asociación sin ánimo de lucro, conformada por esposas de oficiales activos y en uso de buen retiro de una institución militar colombiana, que trabajan de manera voluntaria para garantizar el bienestar integral de los hogares socioeconómicamente más necesitados de una institución militar".

La empresa de carácter social sin ánimo de lucro (ECSSAL) "es una asociación sin ánimo de lucro, conformada por esposas de Oficiales activos y en uso de buen retiro de una institución militar colombiana, que trabajan de manera voluntaria para garantizar el bienestar integral de los hogares socioeconómicamente más necesitados de la institución militar en la ciudad de Cali". La asociación cuenta con seccionales en las diferentes ciudades del país, en donde brinda el servicio de bienestar al personal militar y orgánico de la misma.

Uniendo los dos conceptos anteriormente mencionados y buscando la mejora continua de sus procesos para prestar un mejor servicio a las familias que dependen de esta, dicha institución militar colombiana ha venido realizando un trabajo académico de revisión y diagnóstico de su situación administrativa y operativa indagando un planteamiento estratégico en el apartado logístico que le permita la consecución de sus objetivos. Para este fin, se realizó un diagnóstico de la empresa en cuanto a logística se refiere, caracterizando a la misma y evaluando su competitividad en integración y logística. Esta evaluación, permitió diagnosticar el estado de la empresa en cuanto a competitividad en integración de la supply chain y conocer cómo se desarrolla la logística en la empresa. Esto per- mite preguntar ¿Qué elementos, requerimientos y factores estratégicos logísticos son necesarios para ser implementados en la empresa de carácter social sin ánimo de lucro (Seccional Cali), con el fin de potencializar los logros organizacionales y obtener ventajas competitivas mejorando el servicio al cliente?

\section{Trasfondo Teórico}

Tanto para organizaciones comerciales como para las no lucrativas, la colaboración entre proveedores es un importante recurso estratégico (Balza-Franco et al., 2017). El funcionamiento del sistema logístico de las empresas debe ajustarse a esquemas avanzados y con una elevada formación del personal, lo cual se materializa en el incremento de la competitividad de la misma. Debido a eso las empresas exhiben indicadores con niveles comparables internacionalmente y que reflejan la competitividad del sistema logístico (Del Río Cortina et al., 2009). En ese orden de ideas, se definirán brevemente el marco teórico que incluye aspectos como la logística y la cadena de suministro, la competitividad en integración de la supply chain y la logística y finalmente la planeación estratégica logística.

\section{Competitividad en integración de la supply chain y la logística}

Según el National Council of Physical Distribution Management (1963), en los inicios la logística se identificaba únicamente con la gestión del flujo físico de productos desde el fabricante al cliente. Sin embargo, en la década de los 70's Bowersox (1974) incorpora al concepto anterior la gestión de aprovisionamientos, "otorgando a la logística una nueva dimensión inter-organizacional, que precisa de la coordinación entre las diferentes empresas vinculadas al intercambio" (Servera, 2010).

La competitividad en integración de la supply chain se entiende como la sinergia derivada de los niveles de integración con: Los clientes, para construir a lo largo y ancho de la red características distintivas perdurables con sus clientes; integración interna que les permita integrar sus pro- 
cesos internos con el apoyo a los requerimientos de los clientes; integración con los proveedores en sus procesos internos con los procesos relacionados con sus proveedores; integración de la planeación y la tecnología para soportar una amplia variedad de necesidades operacionales configuradas para atender diversos segmentos del mercado; integración de las relaciones para desarrollar y mantener una estructura mental compartida con clientes y proveedores, en cuánto dependencia inter-empresas y principios de cooperación; y la medición de los niveles de integración para desarrollar y mantener sistemas de indicadores de desempeño - métricas - para facilitar la formulación y ejecución de estrategias de segmentación y optimización de procesos. (Said et al., 2003, p. $3)$.

Para evaluar la competitividad en integración, es necesario medir un conjunto de habilidades, desarrolladas entre los miembros de la supply chain, que se relacionan a continuación (Bowersox et al., p. 29 y ss):

- Integración con clientes: Segmentación de clientes y clientes de clientes; Relevancia, Capacidad de respuesta; Flexibilidad.

-Integración interna: Unificación interfuncional; Estandarización; Simplificación; Aceptación de normas y su cumplimiento; Adaptación estructural.

- Integración con los proveedores: Alineamiento estratégico; Fusión operacional; Encadenamiento financiero; Administración de proveedores y proveedores de los proveedores.

- Integración de la planeación y la tecnología: Administración de la información; Comunicaciones internas; Conectividad; Cooperación en la formulación de pronósticos y en la planeación.

- Integración de las relaciones: Especificidad de los roles; Protocolos; Habilidad para compartir información; Ganancias y riesgos compartidos.

- Medición de los niveles de integración: Evaluación funcional; Metodología de Costeo; Basado en la Actividad y Costo Total;
Indicadores de desempeño o métricas; Impacto financiero.

Según Said et. al (2003) el campo de aplicación del estudio de la competitividad en integración y logística es amplio en tanto sirve como diagnóstico para ser utilizado en el proceso de planeación y gerencia estratégica de la supply chain y logística, como punto de partida para el modelaje de la estructura de la supply chain de la empresa y el diseño de su sistema logístico, como base en la selección o construcción de sistemas de información y comunicación para la supply chain y como punto de partida para el diseño del sistema de logística inversa de la supply chain. Este tipo de estudios está basado en el modelo de Donald J. Bowersox, el cual centra su atención en dos aspectos relevantes: "Competitividad en Integración de la Supply Chain" y "Competitividad en Logística". (p. 3 y ss)

\section{Supply Chain, Supply Chain Management y Logística}

Supply chain y logística no son sinónimos (Said, 2009 , p. 2). Específicamente supply chain no es una cadena de negocios con relaciones uno a uno, sino que es una red de múltiples negocios y relaciones; es decir, es una red adaptativa, inteligente, compuesta por nodos denominados empresas $\mathrm{u}$ organizaciones, pero definitivamente sistemas socio-técnicos (Lambert, 1998).

La estructura de un supply chain o red adaptativa está compuesta por los siguientes elementos: La empresa líder, que jalona el proceso de integración y los nodos de nivel I, II, etc., "aguas arriba" o proveedores y nodos de nivel I, II, etc., "aguas abajo" o clientes, hasta llegar al mar de consumidores o usuarios finales. Para lograr que un supply chain se administre eficientemente, es indispensable construir altos niveles de integración entre los miembros primarios (al menos con los del nivel 1) y secundarios o de soporte. (Said, 2009 , p. 2 y ss).

Según Lambert et al. (2009), las relaciones entre cada uno de los nodos generan vínculos de negocio los cuales se concretan mediante reglas de negocio (propician el mantenimiento de relaciones perdurables entre los miembros de la red). Los 
vínculos pueden clasificarse en: Vínculos de procesos de negocio administrados (en los que la empresa líder se involucra efectivamente en la administración de las relaciones), vínculos de proceso de negocio monitoreados (la empresa líder ejerce un constante y efectivo monitoreo y control de las relaciones), vínculos de proceso de negocio no administrados (la empresa líder no está involucrada activamente, hay mucha confianza en el socio de negocio) y vínculos de proceso de negocio de no participantes (Derivan de decisiones que se toman en otros supply chain (s) y pueden afectar la eficiencia de la empresa líder).

\section{Supply Chain Management desde una pers- pectiva estratégica}

Según The Global Supply Chain Forum (GSCF) existen ocho procesos claves de negocio que pueden ser vinculados a través de la supply chain, los cuales debidamente estandarizados en cada uno de los nodos de la red permiten que esta desarrolle su capacidad de adaptarse, mejore significativamente sus niveles de integración, disminuya el costo total del producto y/o servicio e incremente la calidad de los mismos y mejore la gerencia del servicio, en pocas palabras, ayudan a que la red incremente sus niveles de competitividad. Los procesos que se identificaron son: Administrar las relaciones con el cliente y el proveedor, administrar el servicio al cliente, administrar la demanda, la gestión de la orden, y el flujo de manufactura, administrar el diseño y desarrollo de nuevos productos y servicios y por último administrar el retorno. Cada uno de estos procesos desdobla su complejidad en subprocesos estratégicos y operacionales. (Lambert, 2005).

Este modelo hace hincapié en la importancia de utilizar un enfoque de procesos, para lo cual, es de suma importancia que las relaciones con los principales clientes y proveedores sean estrechas y se desarrollen continuamente (vínculos de negocio administrados). Según el marco GSCF, cuando todos los mecanismos de coordinación adecuados están en su lugar a través de las diferentes funciones, el resultado será una eficiente y eficaz red de valor. (López Roa et al., 2013, p. 41).

\section{Planeación estratégica logística}

La planeación estratégica y la logística son dos de los factores que engloban las necesidades de direccionamiento estratégico de las empresas a nivel mundial. La planeación estratégica permite el análisis de las variables internas y externas para formular los propósitos (misión, visión, objetivos y metas), las estrategias, los planes de acción y los indicadores de desempeño y logro, tanto para la empresa en su totalidad como para cada área de la misma en particular. La logística permite agregar valor e integrar los procesos transversales de la empresa, ya que se ocupa del mejoramiento de actividades desde la compra de materias primas o insumos hasta la distribución y el servicio al cliente en actividades de postventa. (Sánchez, 2003, p. 1).

De lo anterior, la planeación estratégica logística le permite a cualquier empresa realizar un adecuado proceso administrativo para el logro de resultados en integración con los demás miembros de la red de valor. Para lograr esto, se parte de la identificación de las necesidades de los clientes, con el fin de ajustar la estrategia corporativa con la estrategia logística y así asegurar que el supply chain sea capaz de garantizar lo demandado en tiempo, calidad y costos competitivos (Restrepo et al., 2010, p. 90).

\section{Metodología}

\section{Enfoque de la Investigación}

El tipo de investigación que se realizó es de tipo descriptiva. Se procedió a realizar un diagnóstico estratégico que comprende análisis interno (fortalezas y debilidades) y análisis externo (oportunidades y amenazas) y evaluación de situación actual en logística de la empresa, analizando el entorno y las capacidades de la misma, con el fin de caracterizar el sistema logístico y formular estrategias competitivas que permitan optimizar el logro de los objetivos organizacionales.

El enfoque de la investigación es cualitativo y cuantitativo, de modo que se pretendió conocer 
el estado actual de la empresa evaluando y midiendo las mejores prácticas en cuanto a logística se refiere con el fin de proponer y formular estrategias competitivas que le permitan brindar valor agregado a las necesidades del cliente.

\section{Fases Metodológicas}

Documentación bibliográfica: Durante esta fase se realizó la búsqueda de documentos que ayudarán al planteamiento de ideas (elaboración del marco referencial, diseño de instrumentos, elaboración de preguntas que alimenten la entrevista, análisis de la información obtenida) con el fin de solucionar los problemas identificados. Las fuentes de información consultadas fueron material bibliográfico impreso tales como libros, revistas, etc., artículos e información técnica disponibles en internet, bases de datos, repositorios electrónicos, etc.

Diseño de instrumentos: Una vez se tuvo un conocimiento previo de la temática a abordar, se procedió a revisar, ajustar y actualizar el diseño en Excel de las herramientas para la evaluación de la competitividad en integración del SCM y la logística y la caracterización de la logística de la red de valor de la empresa. Ambos instrumentos fueron facilitados por dos docentes (Feres Said y Fabiola Pinzón) de la Maestría en Gestión Logística de la ENAP. En esta etapa se procedió a revisar, ajustar y actualizar los instrumentos, teniendo en cuenta la información encontrada en la literatura sobre los cambios que se han tenido en logística en los últimos años. En la herramienta de caracterización se contaba con trece (13) elementos del modelo, sin embargo, fue actualizada incluyendo el factor de logística humanitaria y la temática de medidas de protección al medio ambiente.

Recolección de la información: En esta fase se procedió a recolectar información de fuentes primarias, mediante la realización de entrevistas realizadas al personal encargado de la logística en las empresas de la red de valor (aguas arriba nivel II, aguas abajo nivel I), la observación y la información cruzada.
Análisis y procesamiento de la información: Con la información obtenida en las entrevistas y la contrastación con lo observado durante las visitas, se procedió a evaluar a la red de valor en las herramientas de Excel diseñadas y con los resultados arrojados por estas a realizar un análisis descriptivo de la información.

Los datos obtenidos en los pasos anteriores se condensaron en una matriz DOFA con la que se identificaron fortalezas y debilidades dentro de la empresa, y oportunidades y amenazas en el medio ambiente y el entorno. Tal información se utilizó para la generación de estrategias logísticas que permitan la identificación y fortalecimiento de la red logística (y sus procesos).

Documentación de la información: En esta fase se organizó la información obtenida en los pasos anteriores y se redactó el capítulo de resultados y las conclusiones y recomendaciones productos de la ejecución del proyecto de grado. En este sentido, se redactó el informe del diagnóstico interno y externo (Caracterización de la logística y el análisis de competitividad e integración de la logística en la empresa), la definición de las estrategias logísticas identificadas teniendo en cuenta la información del análisis DOFA y por último, la formulación de los planes y proyectos estratégicos en logística.

\section{Técnicas e Instrumentos de Recolección de la Información}

Para la recolección de la información se procedió a realizar una entrevista al personal encargado de la logística en las empresas de la red de valor objeto de estudio. Esta información se contrastó con la obtenida a través de la observación de la situación logística de la red de valor de la empresa líder. Con esta información, se evaluó a la red de valor mediante la aplicación de los instrumentos (fichas de Excel) diseñados para medir la competitividad en integración del SCM y la logística, así como la caracterización de la logística de la supply chain.

El instrumento para medir la competitividad de la empresa líder en cuanto a integración y logística, se basó en el modelo de Donald J. 
Bowersox para medir competitividad y consta de 106 preguntas que reflejan las "mejores prácticas" realizadas por empresas de clase mundial, las cuales, se deberían hacer al interior de una empresa para ser más competitiva. Estas 106 preguntas se esbozan en el modelo de Excel como variables y están organizadas en habilidades y estas a su vez, en competencias tanto en competitividad en integración de la supply chain como en logística.

El instrumento para evaluar la caracterización de la logística, presenta 14 elementos que permiten vislumbrar como se encuentra la red de valor de la empresa líder en cuanto a logística se refiere y a partir de este conocimiento for- mular estrategias en logística y gestión de la red de valor, ajustadas a las estrategias de las empresas.

\section{Población y muestra}

De acuerdo con Castro (2003), "si la población es menor a cincuenta (50) individuos, la población es igual a la muestra". En este sentido, para este trabajo la muestra se toma igual que la población en la encuesta" (p.69). En este sentido, el personal encuestado fue: La empresa líder y las empresas de la red de valor aguas arriba (Nivel II) y aguas abajo (Nivel I). Para ampliar la información, véase cuadro1 (observar los cuadros en azul).

\section{Cuadro 1. Lista de proveedores y clientes ECSSAL}

\begin{tabular}{|c|c|c|c|}
\hline Nombre de la empresa & Papel en la red de valor & Unidad de negocio & Nivel \\
\hline ECSSAL & Empresa Líder & - & - \\
\hline Distribuida La Costa S.A & Proveedor de productos de panadería & \multirow[t]{7}{*}{ Panadería } & II \\
\hline La Recetta Soluciones & Proveedor de productos cárnicos & & II \\
\hline Huevos Santa Rita & Proveedor de huevos & & II \\
\hline Quesera Gabriel & Proveedor de productos lácteos & & II \\
\hline Colegio & Cliente & & I \\
\hline Disfruver & Cliente & & I \\
\hline Casino Militar & Cliente & & II \\
\hline Supermercados VIVEREX & Proveedor de víveres y abarrotes & \multirow[t]{3}{*}{ Colegio } & II \\
\hline Copy Rent & $\begin{array}{l}\text { Proveedor de equipos de impresión y } \\
\text { fotocopiado }\end{array}$ & & II \\
\hline Panadería & Proveedor de bollería & & I \\
\hline
\end{tabular}

Fuente: Elaboración propia a partir de información obtenida en la empresa objeto de estudio.

\section{Procesamiento de la Información}

Con la información obtenida en las entrevistas

y su contrastación con lo observado, se procedió a realizar un análisis descriptivo de las respuestas obtenidas haciendo uso de la ponderación de las variables cuestionadas en una herramienta en Excel que permite el análisis de las mismas.
En los archivos de Excel, se puede observar de manera gráfica y numérica los puntos fuertes y las debilidades de la red de valor de la empresa líder, logrando establecer las falencias de la misma y así mismo entrever algunas propuestas de mejora.

El sistema de evaluación que se utilizó para el análisis de las variables y sus componentes es el siguiente (véase cuadro 2): 


\section{Cuadro 2. Sistema de evaluación}

\begin{tabular}{|l|l|}
\hline $\begin{array}{l}\text { Sistema de evaluación. } \\
1\end{array}$ & $\begin{array}{l}\text { Fuertemente en desacuerdo: La información se identifica en absolu- } \\
\text { tamente nada con los atributos que se describen en cada uno de los } \\
\text { elementos del modelo referencial (no se aplica el concepto). }\end{array}$ \\
\hline 3 & $\begin{array}{l}\text { Desacuerdo: La información se identifica mínimamente con los } \\
\text { atributos que se describen en cada uno de los elementos del modelo } \\
\text { referencial (se han tomado decisiones para aplicar el concepto y en } \\
\text { tal sentido forma parte del desarrollo corporativo). }\end{array}$ \\
\hline $\begin{array}{l}\text { Ni en desacuerdo ni de acuerdo: La información se identifica } \\
\text { parcialmente con los atributos que se describen en cada uno de los } \\
\text { elementos del modelo referencial (se aplica el concepto desde hace } \\
\text { poco tiempo y sus resultados no han sido verificados). }\end{array}$ \\
\hline $\begin{array}{l}\text { De acuerdo: La información se identifica significativamente con los } \\
\text { atributos que se describen en cada uno de los elementos del modelo } \\
\text { referencial (se aplica el concepto desde hace más de seis meses, con } \\
\text { buenos resultados). }\end{array}$ \\
$\begin{array}{l}\text { Fuertemente de acuerdo: La información se identifica absolutamen- } \\
\text { te en todo con los atributos que se describen en cada uno de los } \\
\text { elementos del modelo referencial (se aplica el concepto desde hace } \\
\text { más de un año con muy buenos resultados). }\end{array}$ \\
\hline
\end{tabular}

Fuente: Feres Said, 2014

Teniendo en cuenta que cada calificación podría ser catalogada como debilidad (absoluta, relativa) o fortaleza (relativa y absoluta), así:

- Debilidad absoluta (Oportunidad muy grande)

- Debilidad relativa (Oportunidad grande).

- Debilidad (Oportunidad)

-Fortaleza relativa (Mejorar)

- Fortaleza absoluta (Mantener y extender)

Con las evaluaciones y resultados de las fichas en Excel, se procedió a realizar una matriz DOFA para la generación de estrategias logísticas que permitan la identificación y fortalecimiento de la red logística (y sus procesos).

\section{Resultados}

Diagnóstico del Estado Actual de la Logística en la Empresa Teniendo en Cuenta su Competitividad en la Integración de la SCM

En esta sección se iniciará presentando una síntesis general de la empresa líder. Posteriormente, se presentarán los resultados obtenidos con la herramienta de Excel y su evaluación y comporta- miento según las habilidades y competencias de la red de valor.

Generalidades: La Empresa de carácter social sin ánimo de lucro, se encuentra ubicada en la ciudad de Cali (Seccional) y es una organización sin ánimo de lucro, de carácter privado, con patrimonio y personería jurídica propia, que se rige bajo los principios de solidaridad, compromiso social, participación, respeto, libertad y autonomía. Esta organizada bajo las leyes colombianas y la Constitución Nacional, por las regulaciones previstas para las corporaciones en el Código Civil y por sus propios Estatutos. Dentro de su acción voluntaria propende por la creación de programas de orientación social que contribuyan al mejoramiento de la calidad de vida del personal perteneciente a una institución militar colombiana con sede en la ciudad de Cali, con fundamento en el reconocimiento de la dignidad de la persona humana y la realización de los valores esenciales de la convivencia ciudadana a saber: La vida, la justicia y la paz, y fomentar, a través del servicio desinteresado, una conciencia ciudadana generosa y participativa para articular y fortalecer el tejido social (ECSSAL, 2016, p. 1). La empresa Cuenta con un equipo de trabajo de 32 empleados, distribuidos 
entre sus oficinas administrativas y las unidades de negocio (Panadería y Colegio).

Misión: Contribuir al mejoramiento de la calidad de vida del personal activo perteneciente a una institución militar colombiana con sede en la ciudad de Cali, permitiendo con ello la conservación del núcleo familiar y la estabilidad económica y social. (ECSSAL, 2016, p. 2)

Visión: Se proyecta a la empresa como una organización con fines sociales, generadora de recursos, que permita dar cobertura a las necesidades de las familias beneficiarias. (ECSSAL, 2016, p. 2).

Estructura Organizacional: La estructura orgánica actual, resultante de un proceso de modernización, permitió adaptar la empresa al modelo de las organizaciones por procesos, cuya estructura es similar a las entidades sin ánimo de lucro dedicadas a la seguridad social y líderes en el país. Esta nueva concepción, permite administrar más eficaz y eficientemente los recursos asignados y el talento humano de las damas voluntarias, a fin de alcanzar los objetivos institucionales propuestos.

\section{Diagnóstico de Red de Valor}

La estructura de la red de valor de la empresa de carácter social sin ánimo de lucro (ECSSAL), es como se puede observar en la figura 1. Debido a su estructura de negocio la empresa se vislumbra como un holding empresarial, tomando a las unidades de negocio "panadería y colegio" como si fueran proveedores de primer nivel para la empresa.

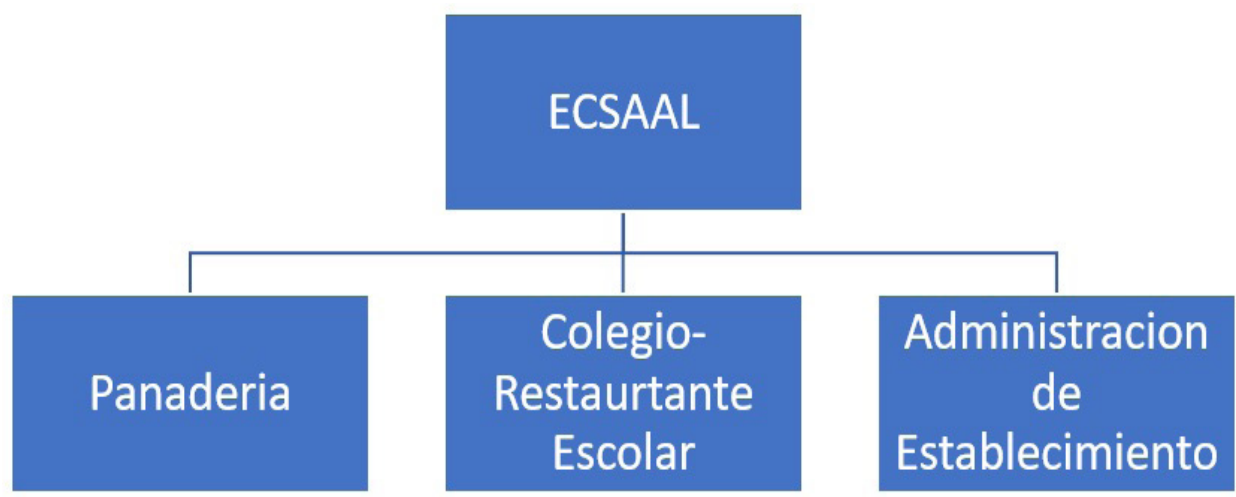

Figura 1. ECSSAL vista como holding empresarial

Fuente: Elaboración propia, basada en datos obtenidos de la empresa objeto de estudio, 2018.

\section{Diagnóstico de la Competitividad en Integración de la Red de Valor}

La integración con los clientes, está relacionada con la capacidad que tiene la empresa para construir relaciones o vínculos perdurables con sus clientes. Del análisis de esta competencia se puede concluir que la empresa como tal no realiza segmentación de clientes para realizar procesos logísticos en general. La relación cliente- empresa líder se da a través de vínculos netamente comerciales y los instrumentos utilizados para el cierre de los negocios son los contratos escritos y los acuerdos verbales. En ellos, se especifica el protocolo de entrega de los productos, las formas de pago (que pueden ser a crédito o débito), y los medios para solicitar un pedido (normalmente se hace por la aplicación WhatsApp o por vía correo electrónico).
En cuanto al concepto de relevancia no existe como tal un programa específico para generar el máximo éxito de los clientes. Sin embargo, se enfocan en entregar sus productos y servicios a tiempo y de la mejor manera con el fin de generar satisfacción en el cliente.

En cuanto a la integración externa, es decir, la capacidad que tiene la empresa para integrar sus procesos internos, con los procesos externos, es decir, con los de sus clientes y proveedores. Del análisis de esta competencia se puede concluir en cuanto a la unificación interfuncional que las operaciones diarias de la empresa como holding empresarial son realizadas por equipos interfuncionales con el fin de agilizar las actividades. En este sentido, la gestión de la empresa se hace por funciones y no por procesos. No se cuenta con una certificación en sistemas de gestión de cali- 
dad, sin embargo, se han realizado esfuerzos en la búsqueda del mismo. La empresa cuenta con una estructura organizacional vertical, lo que no posibilita la oportunidad de tomar decisiones autónomamente, todo debe ser consultado con la junta directiva o como mínimo con la presidencia de la organización

En cuanto al concepto de estandarización, la empresa no tiene como tal formulada unas políticas claras sobre la sincronización de operaciones entre ella y sus socios de negocio. Sin embargo, se han realizado acuerdos verbales con los proveedores y clientes con el fin de esclarecer cómo se hará la entrega de los productos, lo anterior, debido a que la ECSSAL se encuentra ubicada en instalaciones militares y prima la seguridad de la base.

Las personas que colaboran en la empresa, toman para sí (aprehenden) las políticas y procedimientos operacionales y administrativos (aceptación de normas y su cumplimiento). En este sentido, el personal de nómina tiene clara e interiorizan las políticas y procedimientos de la empresa, las cuales, son instruidas al momento de ingresar a la organización y son afianzadas durante su labor diaria. Sin embargo, no existe por escrito un manual de funciones y cargos. Sus salarios son establecidos acorde a su nivel académico. Cabe anotar que el personal de la junta directiva es rotativo. En los estatutos de la empresa está estipulado que la Junta Directiva debe estar conformado por esposas de oficiales, los cuales, dependen de planes de traslado periódicos. Sin embargo, al ser la empresa de carácter social, hay que resaltar que esta junta es compuesta por empleados en voluntariado que tienen un alto sentido de pertenecía por la organización y sus obras sociales en favor del personal militar y sus familias en la ciudad de Cali.

Del concepto de adaptación estructural, la empresa no cuenta con programas en desarrollo para estandarizar y medir los procesos logísticos ni al interior ni con sus socios de negocio aguas arriba y abajo. Por otro lado, la empresa no cuenta con la habilidad para "extender sus procesos internos" aguas arriba y aguas abajo del Supply Chain. Esta extensión solo ocurre con sus proveedores de primer nivel (Panadería y Colegio), de- bido a que hacen parte de la empresa al ser vista como un holding empresarial.

\section{Diagnóstico de Competitividad en Logística}

De acuerdo con la información recabada en la formulación de estrategia logística, no se formulan y ejecutan estrategias de servicios logísticos diferentes para cada cliente. En este sentido, el tratamiento para cada cliente es el mismo. No existe un plan de capacitación permanente en logística para el personal operativo de la empresa. La red de valor de la empresa no comparte información operacional con los socios de negocio. En conclusión la empresa tiene poca habilidad para formular y alcanzar los objetivos logísticos y financieros y para analizarlos frente a los alcanzados por los socios del Supply Chain, aguas arriba y aguas abajo.

En cuanto a la integración logística en la Supply Chain, no hay establecido un procedimiento o plan para establecer sociedades y alianzas con los socios de negocio. Sin embargo, por ser una empresa de carácter social sin ánimo de lucro habitualmente solicita y recibe donaciones para las actividades sociales que hace de parte de empresas que no necesariamente hacen parte de la red de valor. Por otro lado, el esfuerzo de la empresa no se enfoca en integrar las operaciones logísticas entre la empresa y sus proveedores y clientes de tal forma que se logren fusiones operacionales; simplemente, se realizan coordinaciones en cuanto a las entregas de los pedidos realizados (horario, día y quien recibe) bajo contratos comerciales o acuerdos verbales de negocio. En este sentido, no se comparte un sistema de expectativas y procura de esfuerzos para alcanzar las metas propuestas en conjunto. Sin embargo, este concepto se aplica entre la empresa ECSSAL y sus socios de negocio de primer nivel aguas arriba (Panadería y Colegio), en donde se hacen esfuerzos por hacer del negocio un éxito.

Se puede concluir que la empresa tiene clara la forma cómo es el sistema logístico de su empresa, sin embargo, este no se imbrica en el sistema logístico de la Supply Chain para alinear recursos y alianzas estratégicas. 
Del concepto de red logística, se puede decir que la red de valor no contempla o comparte instalaciones de distribución. Las entregas de los pedidos se hacen bajo relaciones comerciales en donde se indica en la orden donde debe ser entregado el producto. Si llegaré a existir una operación de entrega especial para satisfacer un requerimiento especial de algún cliente, simplemente en el momento de la orden, se especifica dónde se debe entregar, la hora y quien recibirá el producto.

Se concluye que la empresa no participa en el diseño de la estructura de la red logística y en la disposición física de los recursos logísticos en la Supply Chain.

En cuanto al tema de organización, las actividades logísticas en la empresa y sus proveedores de primer nivel (panadería y colegio) son realizadas en equipos interfuncionales de tal forma que se agilice las operaciones diarias. Sin embargo, con los demás socios de negocio aguas arriba y abajo no existe esta interfuncionalidad del trabajo en equipo. Las decisiones estratégicas y logísticas de la empresa deben ser consultadas y aprobadas por la Junta Directiva, teniendo en cuenta las políticas establecidas. En este sentido, la empresa tiene una estructura organizacional vertical. En términos generales, no se cuenta con un programa de capacitación formal que capture la experticia y experiencia del personal operativo y administrativo para luego transmitir este conocimiento a los miembros de la red de valor.

Para concluir, se puede decir que la empresa no cuenta con la habilidad para mantener una estructura efectiva de su sistema logístico extendido a la red de valor y para disponer del talento humano (Capital Intelectual) en el sistema logístico.

\section{Integración de la Supply Chain}

Del concepto de unificación de la supply chain, se puede resumir que la empresa no define de manera colaborativa, ni integra operaciones logísticas específicas, responsabilidades o actividades interconectadas con sus socios de negocio. No hace uso de protocolos de servicios para el manejo de las relaciones, para el manejo de estas, se hace uso de contratos legales o acuerdos verbales. Por otro lado, la empresa no tiene vínculos en supply chain con sus socios de negocio que operen bajo el concepto de compartir riesgos y beneficios.

Los procesos de la empresa no se encuentran extendidos a la red de valor. Algunos proveedores cuentan con SI para el manejo de las relaciones con sus clientes, sin embargo, estas capacidades no son tenidas en cuenta en las relaciones entre estos y la empresa ECSSAL. Asimismo, estos cuentan con programas de capacitación y asesorías para sus clientes y proveedores con el fin de potencializar e innovar en los productos ofrecidos. Desde la ECSSAL se está trabajando para aprovechar estas capacidades ofrecidas por sus proveedores. Se puede concluir que la empresa no tiene la habilidad suficiente para establecer, de manera intensiva, relaciones con sus proveedores y clientes en el Supply Chain.

De las tecnologías de la información, la empresa no se encuentra conectada con sus socios de negocio, sus vínculos de negocio con proveedores y clientes son netamente comerciales. A pesar de que algunos socios aguas arriba cuentan con tecnologías de la información para acercar relaciones con sus clientes, estas no son aprovechadas. La empresa cuenta con un Sistema de Información para el control de la contabilidad y los inventarios. Este SI no se encuentra extendido a la red de valor. De lo anterior, se puede concluir que la empresa no ha invertido en TIC's para procesar e intercambiar datos e información y para facilitar la toma de decisiones en tiempo real en la Supply Chain.

Por otro lado, hablando del concepto de información compartida, en la red de valor no se comparte o intercambia información de indicadores logísticos o de la gestión logística, con el fin de facilitar la toma de decisiones. La empresa no ha definido indicadores logísticos para medir su gestión y tampoco cuenta con TIC para hacer extendida a sus socios de negocio esta información. De este concepto se puede concluir que la empresa no cuenta con la habilidad para compartir información operacional y estratégica logística, financiera, técnica y operacional, con clientes y proveedores.

En cuanto a la conectividad, la empresa no ha invertido en TIC con el fin de intercambiar o 
compartir información o datos entre los socios de negocio que faciliten la gestión logística. Los procesos de la empresa no se encuentran extendidos a la red de valor y estos no están en la capacidad para compartir internamente, tanto información estándar como específica con clientes y proveedores. Se puede concluir que la empresa no intercambia información confidencial con los socios del Supply Chain, aguas arriba y aguas abajo, en determinados momentos y bajo un formato de responsabilidad en su uso.

De la estandarización, se puede decir que la empresa no ha participado en la formulación de procedimientos o políticas para facilitar las operaciones logísticas, mediante estándares organizacionales y tecnológicos. Es decir, para la estandarización de las operaciones logísticas en común y para el intercambio de datos. Tampoco se han generado programas de incentivos orientado al personal operativo para estimular la generación de mejores prácticas en SCM y logística.

Del concepto de simplificación, la empresa no ha cambiado notablemente sus instalaciones físicas y la complejidad de sus operaciones como mecanismo para incrementar el EVA. Asimismo, la empresa no ha diseñado en profundidad procesos y procedimientos en SCM y logística. Se puede decir que la empresa no ha diseñado rutinas y procedimientos de trabajo que mejoran la eficiencia, eficacia y efectividad del sistema logístico.

En cuanto a la disciplina, la confiabilidad de la empresa en cuanto a las entregas de pedidos a sus clientes ha mejorado en los dos últimos años. Sin embargo, no se dispone de métricas o estadísticas. Los salarios, incentivos y bonificaciones en la empresa, estimulan la adhesión a las políticas, procesos y procedimientos establecidos. Sin embargo, la empresa no tiene programas en desarrollo para estandarizar y medir procesos logísticos. Se puede decir que la empresa fomenta en el recurso humano operativo y administrativo, la aprehensión de políticas y normas que buscan el éxito de la organización y la satisfacción de los clientes.

\section{Caracterización del Sistema Logístico de la Empresa de Carácter Social sin Ánimo de Lu- cro}

En la Figura 2 y en el cuadro 3, se muestran los resultados del análisis de los elementos del modelo referencial aplicado a la red de valor de la empresa líder.

\section{Cuadro 3. Resultados de Modelo}

\begin{tabular}{|l|l|l|l|l|l|l|}
\hline \multicolumn{1}{|c|}{ ELEMENTO DEL MODELO } & $\begin{array}{c}\text { C A L I F I C A - } \\
\text { CION }\end{array}$ & $\begin{array}{c}\text { M I N I - } \\
\text { MA }\end{array}$ & $\begin{array}{c}\text { M A X I - } \\
\text { MA }\end{array}$ & MEDIA & $\begin{array}{c}\text { DESVIACION } \\
\text { ESTANDAR }\end{array}$ & $\begin{array}{c}\text { O B S E R VA - } \\
\text { CION }\end{array}$ \\
\hline CONCEPTO LOGISTICO & 2,11 & 2,00 & 3,00 & 2,11 & 0,33 & Debilidad \\
\hline ORGANIZACION Y GESTION LOGISTICA & 2,09 & 2,00 & 3,00 & 2,09 & 0,30 & Debilidad \\
\hline TECNOLOGIA DE ALMACENAJE & 3,15 & 2,00 & 4,00 & 3,15 & 0,90 & Oportunidad \\
\hline TECNOLOGIA DE MANIPULACION & 3,00 & 2,00 & 4,00 & 3,00 & 0,82 & Oportunidad \\
\hline $\begin{array}{l}\text { TECNOLOGIA DE TRANSPORTE INTER- } \\
\text { NO }\end{array}$ & 2,13 & 1,00 & 3,00 & 2,13 & 0,64 & Debilidad \\
\hline $\begin{array}{l}\text { TECNOLOGIA DE TRANSPORTE EXTER- } \\
\text { NO }\end{array}$ & 2,64 & 1,00 & 3,00 & 2,64 & 0,67 & Oportunidad \\
\hline TECNOLOGIA DE INFORMACION & 2,89 & 2,00 & 4,00 & 2,99 & 0,78 & Oportunidad \\
\hline TECNOLOGIA DE SOFTWARE & 2,73 & 2,00 & 4,00 & 2,73 & 0,90 & Oportunidad \\
\hline TALENTO HUMANO & 2,46 & 1,00 & 4,00 & 2,45 & 0,93 & Debilidad \\
\hline INTEGRACION DEL SUPPLY CHAIN & 1,50 & 1,00 & 2,00 & 1,50 & 0,55 & Debilidad \\
\hline BARRERAS DEL ENTORNO & 1,50 & 1,00 & 2,00 & 1,50 & 0,58 & Debilidad \\
\hline LOGISTICA REVERSA & 2,67 & 2,00 & 3,00 & 2,67 & 0,50 & Oportunidad \\
\hline MEDIDA DEL DESEMPENO LOGISTICO & 1,60 & 1,00 & 2,00 & 1,50 & 0,53 & Debilidad \\
\hline LOGÍSTICA JUSTA Y HUMANITARIA & 2,00 & 2,00 & 2,00 & 2,00 & 0,00 & Debilidad \\
\hline Calificación Final & 2,31 & 0,00 & 0,00 & 0,00 & 0,00 & Debilidad \\
\hline
\end{tabular}

Fuente: Ficha “Caracterización de la logística empresa objeto de estudio", 2018 


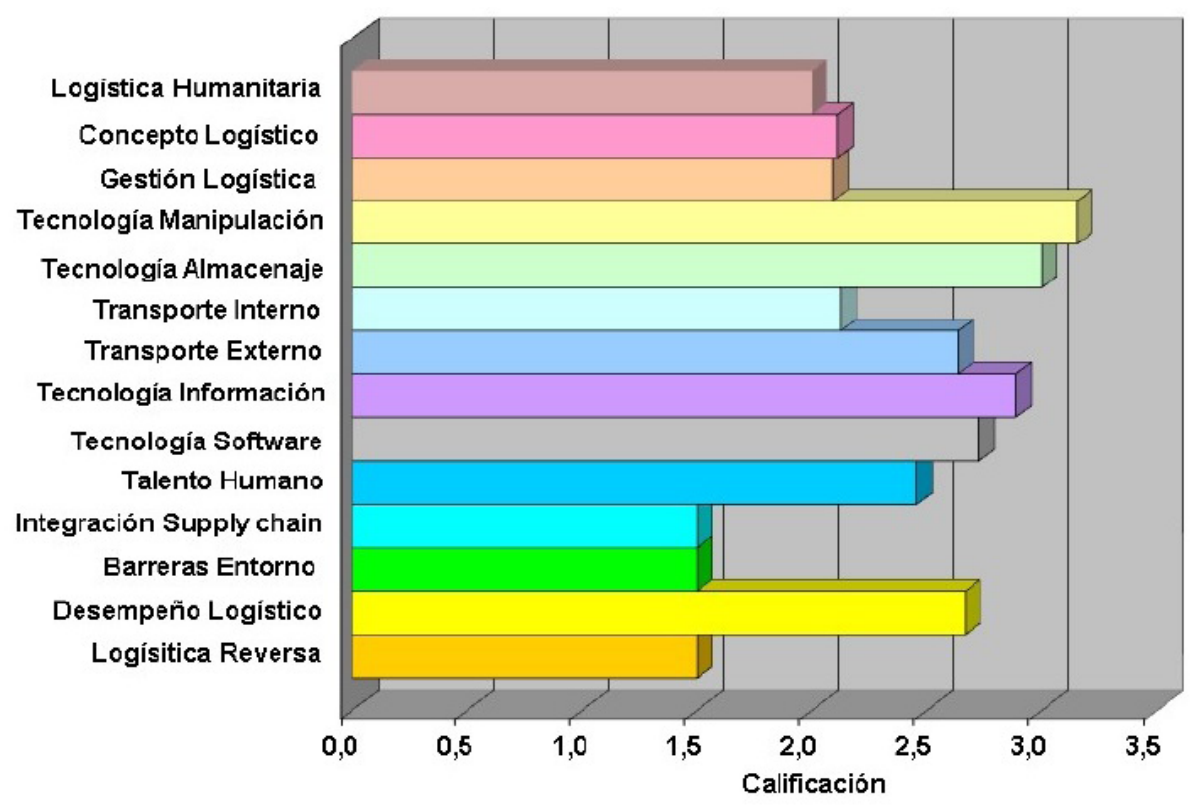

\section{Figura 2. Resultados del modelo}

Fuente: Ficha "Caracterización de la logística empresa objeto de estudio", 2018.

De los resultados obtenidos se puede observar que el modelo referencial de la empresa es una debilidad relativa (2,31), lo cual quiere decir, que en términos generales cada uno de los elementos puede generar oportunidades significativas para diseñar estrategias que mejoren estos resultados. A continuación se hará un análisis a partir de los elementos de la caracterización de la logística en la empresa líder.

La empresa está organizada bajo una estructura vertical jerárquica (organización convencional), con silos funcionales básicos. Su forma organizativa no privilegia y fomenta la armonía de las relaciones dentro de la empresa y sus relaciones con sus socios de negocio aguas arriba y abajo, lo cual, no utiliza como estrategia para incrementar su competitividad. En este sentido, la empresa no ha incursionado en la alternativa de integración con clientes y proveedores a partir de la implementación de enfoques organizativos creativos (SCM o gestión de Redes de valor). Su modelo de gestión logística no es efectivo para virar de una organización vertical a una horizontal o extendida.

Asimismo, la empresa no cuenta con una persona exclusiva para el manejo de la logística en la empresa (gerencia logística o de operaciones). En este sentido, las funciones tácticas y operativas son realizadas por los mismos empleados admi- nistrativos y operativos en la medida que se van presentando las necesidades logísticas y estos no pueden tomar decisiones de ninguna índole, pues todo debe ser consultado y aprobado por la junta directiva (algunas decisiones tácticas pueden ser tomadas por la presidente de la empresa). Lo anterior vislumbra que la empresa no toma sus decisiones organizativas (estratégicas, tácticas y operativas) a partir del pensamiento en redes o trabajo C3 (en coordinación, colaboración y cooperación con los socios de negocio).

pesar de que no existe está integración, si hay evidencia de flujo constante de materia (bienes y servicios), energía e información de las transacciones comerciales realizadas entre la empresa líder y sus socios de negocio. En conclusión, la empresa no aplica estrategias de integración basada en Supply Chain Management y su sistema logístico no transciende la empresa.

En cuanto a la planeación, la empresa como unidad no formula planes estratégicos logísticos ni colaborativos en SCM y logística. No concibe la integración de la planeación y la tecnología, como un factor crítico de éxito, en la reducción del costo total, el alineamiento recursos, y el mejoramiento del servicio al cliente y al consumidor y/o usuario final.

En términos generales, la empresa objeto de estudio obtuvo una valoración promedio de 2.11/5.0, 
esto indica que SE IDENTIFICAN MINIMAMENTE con los atributos de la mejor práctica en lo relativo al "concepto logístico".

\section{Organización y gestión logística}

Los ejecutivos de la empresa mínimamente tienen claro y están de acuerdo que las empresas exitosas ya no compiten exclusivamente entre ellas, sino entre Redes de Valor, lo que implica pasar de un modelo de gestión organizacional vertical, a un modelo organizacional horizontal, lateral o federado.

El modelo de gestión logística de la empresa facilita mínimamente la tarea de virar desde una organización vertical, a una horizontal o lateral, en tanto, no se formulan y desarrollan de manera colaborativa, coordinada y cooperada (C3) planes estratégicos en logística, el sistema logístico de la empresa no se imbrica en la red de valor; no está diseñado para servir a los intereses de la supply chain y no se cuenta con un sistema de información y comunicación que igualmente alcance a todos los socios de negocio sirviendo a los intereses de la red de valor. Asimismo, no se utilizan formas de trabajo avanzadas en C3, tales como silos funcionales o clúster. Lo anterior dificulta alcanzar altos niveles de integración, productividad y competitividad.

Las operaciones logísticas en la empresa se desarrollan bajo silos funcionales básicos (formados por los mismos trabajadores administrativos y operativos) que reportan su actividad a la presidenta y a la junta directiva.

De otra parte, a pesar de que en los estatutos de la empresa se habla de que la estructura organizacional es por procesos, se evidencia que el sistema logístico no tiene en operación los procesos estratégicos y tácticos en supply chain management. En la empresa no existe una base documental en la cual se plasman las políticas, objetivos estratégicos, estrategias, mapa de procesos, procedimientos y normas, como resultado de un proceso de implementación de un Sistema de Gestión (Calidad, control y seguridad). Sin embargo, se conoce que ha habido intentos por parte de la junta directiva y miembros de la asamblea general por documentar la información estratégica y las actividades claves y de apoyo que ejecuta la empresa en su día a día. Durante la visita se pudieron ver y leer algunos de los procedimientos ya documentados.

En términos generales, la empresa obtuvo una valoración promedio de 2,09/5.0, esto indica que SE IDENTIFICA MÍNIMAMENTE con los atributos de la mejor práctica en lo relativo a "organización y gestión logística".

\section{Integración de la Supply Chain}

La empresa no tiene modelada la tipología y configuración genérica de su Supply Chain, ni diseña y/o procedimentan protocolos con clientes y proveedores clave.

La empresa no tiene en operación los procesos estratégicos y tácticos en Supply Chain. En este sentido, las relaciones con clientes y proveedores y los procesos logísticos no se han diseñado y procedimentado de conformidad con los protocolos (PSA) que se acuerdan con clientes y proveedores, previa la segmentación de los mismos, y conforme a sus necesidades logísticas. Sus relaciones son netamente comerciales, que se acuerdan en contratos legales y otros en acuerdos verbales.

En la empresa existe mínimamente una franca convicción sobre el principio y trabajo en Coordinación, Colaboración y Cooperación (C3) en la red. En la actualidad, la empresa se encuentra en la búsqueda de "integración" con sus clientes y proveedores. A través del establecimiento de alianzas de capacitación con uno de sus proveedores buscan aprovechar el conocimiento brindado por este para la generación de nuevas empresas a partir de los productos que se ofrecen. Asimismo, se ha generado una página web para la comunicación con los padres de familia, consumidores de la unidad de negocio "colegio", con el fin de facilitar los procesos académicos. Lo anterior, buscando también el desarrollo de la capacidad de respuesta al cliente, el desarrollo de la capacidad cultural, y el estilo de liderazgo.

La empresa y sus socios de negocio no se encuentran conectadas mediante Sistemas de Información y Comunicación que permitan y faciliten el enfoque (C3) Colaboración, Coordinación, Cooperación, en procesos de planeación estratégica, 
planeación de la demanda, pronósticos de la demanda, logística, servicio al cliente, y desarrollo y comercialización de nuevos productos. Sin embargo, algunos proveedores cuentas con CRM y ERP que pueden facilitar la gestión de las relaciones de negocio, siempre y cuando estos sean ofrecidos y aprovechados por la empresa líder, situación que no se da actualmente.

En términos generales, la empresa obtuvo una valoración promedio de 1,5/5.0, esto indica que se IDENTIFICA EN NADA con los atributos de la mejor práctica en lo relativo al elemento "integración de la supply chain”.

\section{Medidas del desempeño logístico}

En la empresa el funcionamiento del sistema logístico se ajusta en absolutamente nada a esquemas avanzados en SCM y logística. No se cuenta con una elevada formación del personal, lo que se materializa en el decrecimiento de la competitividad del mismo.

No se han diseñado KPIs en la empresa de tal forma que estos permitan tomar decisiones estratégicas efectivas, en el momento oportuno; Por lo tanto, no están disponibles de manera on line para soportar las relaciones con los socios de negocio de la red de valor.

En la empresa no se han establecido equipos de trabajo dedicados a diseñar y mantener el sistema de métricas, de conformidad con la tipología y configuración del Supply Chain, los protocolos o PSA(s) establecidos para clientes o proveedores. Asimismo, no se han realizado de manera sistemática estudios Benchmarking en SCM y Logística, dentro de su propia industria y fuera de ella. Sin embargo, si cuentan con un estudio de benchmarking sobre su estructura organizacional y operativa. Dicho estudio fue realizado por un par de estudiantes de pregrado como requisito para graduarse como profesionales.

\section{Logística humanitaria}

A pesar de ser una empresa de carácter social, la empresa no tiene conocimiento sobre el Decreto 4147 del 3 de diciembre de 2011, que tra- ta sobre la creación de la Unidad Nacional para la Gestión del Riesgo de Desastres. Lo anterior revela que la empresa no participa en el proceso de implementación de la gestión del riesgo de desastres de conformidad con las políticas de desarrollo sostenible, ni en los procesos de coordinación, funcionamiento y desarrollo continuo del Sistema Nacional para la Prevención y Atención de Desastres. En la empresa no se evidenció la formulación de programas de capacitación en logística humanitaria y sobre la gestión del riesgo de desastres, con el fin de tener claridad en cómo puede la empresa apoyar en posibles eventos adversos derivados de conflictos armados, guerras, catástrofes naturales o artificiales, etc., mediante la pertenencia a redes nacionales e internacionales.

La empresa obtuvo una valoración de 2.0/5, esto indica que se IDENTIFICA MÍNIMAMENTE con los atributos de la mejor práctica en lo relativo a "Logística humanitaria".

\section{Vulnerabilidad (Barreras del entorno logístico)}

En la empresa no se conoce el concepto de mapas concéntricos de vulnerabilidad. En cuanto a logística se refiere, no existe un proceso que permite establecer el nivel de vulnerabilidad del sistema logístico, en los cuales se ploteen y analicen los eventos adversos que podrían ocurrir y la generación de planes de acción de contingencia a estas situaciones. En este sentido, el concepto de robustez empresarial, no se aplica. No se conoce la probabilidad de que un evento adverso ocurra; por ende, los planes de acción pertinentes para solventar la situación adversa y regresar en el menor tiempo posible a la situación normal, no existen. Asimismo, no se evidencian procesos de capacitación en cuanto a vulnerabilidad y resiliencia. Teniendo en cuenta que la empresa no se encuentra integrada con los socios de negocio de la red, no existe un proceso de investigación permanente sobre vulnerabilidad de la supply chain y de su Sistema Logístico.

No se formulan en colaboración los planes de acción respectivos y los procesos de capacitación permanente en cuanto a la ocurrencia de 
eventos adversos y qué hacer en caso de que estos se presenten.

La empresa obtuvo una valoración de 1,5/5.0, esto indica que se IDENTIFICA EN NADA con los atributos de la mejor práctica en lo relativo a "Vulnerabilidad (Barreras del entorno logístico)".

\section{Retorno y logística inversa}

En la empresa existe parcialmente una política clara sobre la administración del retorno (operaciones de logística inversa). En este sentido, la empresa cuenta con un documento en el que se define qué hacer con los activos que se van a sacar del inventario, en especial aquellos que pueden generar un impacto negativo en el medio ambiente como equipos de cómputo, equipos electrónicos y maquinaria pesada. En cuanto a los desechos o residuos de la panadería, el colegio y las unidades de arrendamiento, estos han acogido la política medioambiental de la unidad militar (esta unidad está certificada en NTC GP 1000, ISO 14000 y OSHA 18000) en la que se encuentra ubicada la empresa.

\section{Tecnología de almacenamiento}

La empresa cuenta con una bodega en cada una de las instalaciones de sus unidades de negocio, la cual está ajustada a las necesidades de almacenamiento. Estas bodegas son administradas por la empresa objeto de estudio y no se tiene en cuenta los socios de negocio para determinar en dónde se ubican las bodegas, quienes son los responsables de su administración, y qué tecnologías deben utilizar.

En las bodegas, se utilizan medios que permiten la utilización máxima en altura y área, buscando garantizar la organización de la materia prima, catalogándose de acuerdo al tipo de materia prima y su conservación. Sin embargo, no se cuenta con un SI que permita tener un control y conocimiento a priori del inventario de las mismas (salidas y entradas). Esta labor es realizada por los mismos operarios y administrativos, quienes controlan manualmente los inventarios y las necesidades de aprovisionamiento. En este sentido, en las bodegas, las operaciones no se llevan a cabo utilizando sistemas automáticos, de tal ma- nera que el hombre no entra en contacto con los productos o mercancías.

La empresa obtuvo una valoración de 3.15/5.0, esto indica que se IDENTIFICA PARCIALMENTE con los atributos de la mejor práctica en lo relativo a "Tecnología de almacenamiento".

\section{Tecnología de información}

En la empresa no se hace uso efectivo de la Tecnología de Información y Comunicación, en forma estándar, Downstream y Upstream, de manera (C3) Coordinada, Colaborativa y Cooperada. Se hace uso de TIC's como Computadores, telefonía móvil, internet, intercambio electrónico de documentos (vía correo electrónico) e internet.

En la empresa no se formulan planes estratégicos en TICs, de manera (C3) Coordinada, Colaborativa y Cooperada downstream y upstream, con el propósito de estandarizarla, disminuir costos y facilitar el proceso de comunicación. El proceso de externalización de los procesos relacionados con Sistemas de Información y Comunicación, no se encuentra establecido o procedimentado en la empresa objeto de estudio. El sistema de información de la empresa no se encuentra extendido en la red de valor.

La empresa obtuvo una valoración de 2,89/5.0, esto indica que se IDENTIFICA PARCIALMENTE con los atributos de la mejor práctica en lo relativo a "Tecnología de información".

\section{Procesos Logísticos}

Los procesos logísticos que se han identificado en la empresa objeto de estudio son: Planeación, aprovisionamiento (compra), producción (manufactura), distribución y retorno. Los procesos logísticos que se implementan de alguna manera en la empresa se dan desde una perspectiva transaccional (enfoque SCOR), el cual está orientado a la táctica, se efectúan dentro de la empresa y eventualmente estos procesos se conectan con los miembros del SC. Algunos procesos estratégicos se dan de alguna manera también en la empresa, como lo son, la administración de las relaciones con el cliente y el proveedor, administrar el servicio al cliente, administrar la orden, administrar el flujo de manufactura, administrar el retorno y administrar la orden. Sin embargo, para la empre- 
sa estos no trascienden a la red de valor (socios de negocios). La empresa pertenece al club de los desconectados.

\section{Planeación}

La planeación que se hace es realizada internamente, no teniendo en cuenta a los miembros de la red de valor. Dentro de los subprocesos identificados están: alinear el aprovisionamiento con la demanda (en función de las necesidades del consumidor o usuario final), administración del inventa- rio (esta se da internamente y no con los socios de negocio aguas arriba y abajo) y compras.

\section{Formulación de Estrategias Competitivas}

continuación, se muestra el análisis DOFA (véase cuadro 4) en cuanto al tema logística y gestión de la red de valor. Esta matriz es resultado de los estudios de competitividad en integración del SCM y la logística en la red de valor y la caracterización de la logística de la empresa.

\section{Cuadro 4. Matriz DOFA}

\begin{tabular}{|c|c|c|c|}
\hline $\begin{array}{l}\text { FORTALEZAS (Atributos de la em- } \\
\text { presa) }\end{array}$ & $\begin{array}{l}\text { OPORTUNIDADES (Atri- } \\
\text { butos del ambiente) }\end{array}$ & $\begin{array}{l}\text { DEBILIDADES (Atributos de la } \\
\text { empresa) }\end{array}$ & $\begin{array}{l}\text { A M E N A Z A S } \\
\text { (Atributos del } \\
\text { ambiente }\end{array}$ \\
\hline $\begin{array}{l}\text { Por ser empresa sin ánimo de lucro, } \\
\text { puede tener facilidades en cuanto a } \\
\text { tener acceso a capital cuando se re- } \\
\text { quiera. }\end{array}$ & $\begin{array}{l}\text { Sistemas y tecnologías de } \\
\text { información de los socios de } \\
\text { negocio aguas arriba y abajo. }\end{array}$ & $\begin{array}{l}\text { Falta de integración con los socios } \\
\text { de negocio. Las relaciones con pro- } \\
\text { veedores y clientes están basadas en } \\
\text { el ámbito netamente comercial. }\end{array}$ & $\begin{array}{l}\text { Reforma Tribu- } \\
\text { taria Impuesta } \\
\text { en el año } 2017 \text { a } \\
\text { personas Jurídi- } \\
\text { cas }\end{array}$ \\
\hline $\begin{array}{l}\text { Se realiza un buen análisis de los pro- } \\
\text { veedores y los materiales que ellos } \\
\text { brindan a la empresa (calidad, precio } \\
\text { y servicio al cliente) }\end{array}$ & $\begin{array}{l}\text { Alianzas estratégicas con los } \\
\text { socios de negocio aguas arri- } \\
\text { ba y abajo. }\end{array}$ & $\begin{array}{l}\text { No hay un aprovechamiento de las } \\
\text { relaciones con el proveedor. No } \\
\text { existen alianzas estratégicas o pro- } \\
\text { yectos de asociatividad concebidos } \\
\text { bajo enfoques de SCM. }\end{array}$ & $\begin{array}{l}\text { La inflación por } \\
\text { la que atraviesa } \\
\text { el país en una } \\
\text { crisis económica. }\end{array}$ \\
\hline $\begin{array}{l}\text { En términos generales es buena la ca- } \\
\text { pacidad de respuesta ante los requeri- } \\
\text { mientos de los proveedores. }\end{array}$ & $\begin{array}{l}\text { Algunos de sus proveedores } \\
\text { cuentan con sistemas de tra- } \\
\text { zabilidad que permiten esta- } \\
\text { blecer la identificación y lo- } \\
\text { calización de los productos. }\end{array}$ & $\begin{array}{l}\text { No existe claridad en cuanto a pla- } \\
\text { neación y análisis estratégico corpo- } \\
\text { rativo. }\end{array}$ & $\begin{array}{l}\text { Aumento en el } \\
\text { precio de los in- } \\
\text { sumos y materias } \\
\text { primas. }\end{array}$ \\
\hline $\begin{array}{l}\text { Buen conocimiento de las capacidades } \\
\text { disponibles, requeridas, utilizadas y el } \\
\text { nivel de stocks. }\end{array}$ & $\begin{array}{l}\text { Las entidades sin ánimo de } \\
\text { lucro cuentan con régimen } \\
\text { tributario especial }\end{array}$ & $\begin{array}{l}\text { No existe planeación estratégica lo- } \\
\text { gística en la empresa. La planeación } \\
\text { táctica y operativa no es extendida a } \\
\text { la red de valor. }\end{array}$ & $\begin{array}{l}\text { Cambios en el } \\
\text { contexto político } \\
\text { y económico. }\end{array}$ \\
\hline La empresa está exenta de impuestos & $\begin{array}{l}\text { La ley permite las pasantías } \\
\text { para jovenes universitarios } \\
\text { dentro de empresas. }\end{array}$ & $\begin{array}{l}\text { Junta directiva poco estable (Direc- } \\
\text { cionamiento estratégico variable). }\end{array}$ & $\begin{array}{l}\text { Creciente poder } \\
\text { de negociación } \\
\text { de los proveedo- } \\
\text { res. }\end{array}$ \\
\hline $\begin{array}{l}\text { Precios competitivos al cliente y con- } \\
\text { sumidor final (calidad y bajos precios). }\end{array}$ & $\begin{array}{l}\text { Capacidad de respuesta de } \\
\text { los proveedores ante reque- } \\
\text { rimientos express de la em- } \\
\text { presa. }\end{array}$ & $\begin{array}{l}\text { Poco o ningún personal enfocado } \\
\text { específicamente al área de la logís- } \\
\text { tica empresarial. }\end{array}$ & $\begin{array}{l}\text { Empresas del } \\
\text { mismo core bus- } \\
\text { sines más com- } \\
\text { petitivas. }\end{array}$ \\
\hline $\begin{array}{l}\text { El personal que labora y hace parte } \\
\text { de la empresa tiene un alto sentido de } \\
\text { pertenencia, compromiso y colabora- } \\
\text { ción con la organización. Además es } \\
\text { creativo. }\end{array}$ & $\begin{array}{l}\text { La experticia en logística y } \\
\text { administración del personal } \\
\text { voluntariado de la empresa. }\end{array}$ & $\begin{array}{l}\text { Sus directivas podrían tener desco- } \\
\text { nocimiento del tema de manejo ge- } \\
\text { rencial (estratégico y logístico) de } \\
\text { una empresa. }\end{array}$ & $\begin{array}{l}\text { Plan traslado de } \\
\text { oficiales de la } \\
\text { unidad militar. }\end{array}$ \\
\hline $\begin{array}{l}\text { Bajo índice de accidentalidad en la } \\
\text { empresa. }\end{array}$ & $\begin{array}{l}\text { Conocimiento del mercado } \\
\text { local, cantidad que se con- } \\
\text { sume en la unidad militar, } \\
\text { preferencias de los consu- } \\
\text { midores, en qué momento se } \\
\text { incrementa ese consumo, etc. }\end{array}$ & $\begin{array}{l}\text { El personal administrativo y opera- } \\
\text { tivo no acredita conocimiento y for- } \\
\text { mación en SCM y logística }\end{array}$ & - \\
\hline $\begin{array}{l}\text { Existe una planeación para la reparti- } \\
\text { ción de las utilidades y es racional. }\end{array}$ & $\begin{array}{l}\text { Tecnologías disponibles en } \\
\text { logística a precios asequi- } \\
\text { bles. }\end{array}$ & $\begin{array}{l}\text { No existen relaciones C3 (Coordina- } \\
\text { ción, Colaboración y Cooperación) } \\
\text { con los socios de negocio aguas } \\
\text { arriba y abajo para la formulación } \\
\text { de planes y proyectos (en SI, TIC, } \\
\text { capacitación, procesos logísticos) }\end{array}$ & - \\
\hline $\begin{array}{l}\text { Bajo índice de accidentalidad en la } \\
\text { empresa. }\end{array}$ & $\begin{array}{l}\text { Conocimiento del mercado } \\
\text { local, cantidad que se con- } \\
\text { sume en la unidad militar, } \\
\text { preferencias de los consu- } \\
\text { midores, en qué momento se } \\
\text { incrementa ese consumo, etc. }\end{array}$ & $\begin{array}{l}\text { El personal administrativo y opera- } \\
\text { tivo no acredita conocimiento y for- } \\
\text { mación en SCM y logística }\end{array}$ & - \\
\hline
\end{tabular}

Fuente: Elaboración propia, con base en datos obtenidos de las fichas de competitividad en integración y logística y caracterización de la logística, 2018. 


\section{Matriz de Estrategias}

En el cuadro 5 se muestras las estrategias competitivas que han sido identificadas y formuladas con el fin de mitigar las falencias encontradas en los análisis anteriores.

\section{Cuadro 5. Matriz de estrategias}

\begin{tabular}{|c|c|c|}
\hline & Fortalezas & Debilidades \\
\hline \multirow[t]{9}{*}{ Oportunidades } & $\begin{array}{l}\text { Establecer alianzas estratégicas con los socios de } \\
\text { negocios aguas arriba, mediante la formulación } \\
\text { e implementación de PSA's, para: Capacitación, } \\
\text { aprovechamiento de TIC's y SI (extendidos en la } \\
\text { red de valor), integración de procesos logísticos, } \\
\text { manejo de indicadores de gestión y desempeño lo- } \\
\text { gístico. }\end{array}$ & $\begin{array}{l}\text { Consolidar las relaciones con los proveedores, generando } \\
\text { proyectos de asociatividad concebidos bajo enfoques de } \\
\text { SCM y logística, buscando ser competitivas y producti- } \\
\text { vas. }\end{array}$ \\
\hline & $\begin{array}{l}\text { Incorporar personal pasante en niveles técnicos y } \\
\text { profesional para fortalecer el área de la logística en } \\
\text { la empresa. }\end{array}$ & $\begin{array}{l}\text { Elaborar un plan de mejoramiento en competencias, para } \\
\text { el personal administrativo y operativo. }\end{array}$ \\
\hline & $\begin{array}{l}\text { Formular plan de capacitación en logística y SCM } \\
\text { para el personal administrativo y operativo de la } \\
\text { empresa, con el fin de generar buenas prácticas al } \\
\text { interior de los procesos logísticos. }\end{array}$ & $\begin{array}{l}\text { Realizar el direccionamiento estratégico corporativo, } \\
\text { aprovechando las capacidades y conocimientos de las } \\
\text { damas voluntarias de la empresa, con el fin de establecer } \\
\text { estrategias y políticas corporativas a largo plazo. }\end{array}$ \\
\hline & $\begin{array}{l}\text { Establecer e implementar procesos de administra- } \\
\text { ción de cadenas de suministro, permitiendo venta- } \\
\text { jas competitivas en tiempo, lugar y costo. }\end{array}$ & $\begin{array}{l}\text { Estandarizar y certificar los procesos y actividades claves } \\
\text { de la empresa, promoviendo los procesos de implemen- } \\
\text { tación de Sistemas de Gestión (Calidad, control y segu- } \\
\text { ridad) como una vía para llegar a estadios de excelencia } \\
\text { empresarial. }\end{array}$ \\
\hline & $\begin{array}{l}\text { Evaluar en el mercado SI y TIC existentes en am- } \\
\text { bientes web que se adapten a las características } \\
\text { logísticas de la empresa para la captura, procesa- } \\
\text { miento de datos e información y generación de co- } \\
\text { nocimiento sobre las operaciones y transacciones } \\
\text { que tengan su origen en la actividad de la empresa. }\end{array}$ & $\begin{array}{l}\text { Establecer relaciones C3 (cooperación, colaboración y } \\
\text { coordinación) con los socios de negocio en la red de va- } \\
\text { lor, con el fin de optimizar los procesos logísticos. }\end{array}$ \\
\hline & & $\begin{array}{l}\text { Establecer alianzas estratégicas con los socios de nego- } \\
\text { cios aguas arriba, mediante la formulación e implemen- } \\
\text { tación de PSA's, para: Capacitación, aprovechamiento de } \\
\text { TIC's y SI (extendidos en la red de valor), integración de } \\
\text { procesos logísticos, manejo de indicadores de gestión y } \\
\text { desempeño logístico. }\end{array}$ \\
\hline & & $\begin{array}{l}\text { Incorporar personal pasante en niveles técnicos y profe- } \\
\text { sional para fortalecer el área de la logística en la empresa. }\end{array}$ \\
\hline & & $\begin{array}{l}\text { Formular plan de capacitación en logística y SCM para el } \\
\text { personal administrativo y operativo de la empresa, con el } \\
\text { fin de generar buenas prácticas al interior de los procesos } \\
\text { logísticos. }\end{array}$ \\
\hline & & $\begin{array}{l}\text { Establecer e implementar procesos de administración de } \\
\text { cadenas de suministro, permitiendo ventajas competitivas } \\
\text { en tiempo, lugar y costo. }\end{array}$ \\
\hline
\end{tabular}

\begin{tabular}{|c|c|c|}
\hline & Fortalezas & Debilidades \\
\hline \multirow[t]{3}{*}{ Amenazas } & $\begin{array}{l}\text { Realizar campaña de marketing a la comunidad ca- } \\
\text { leña mostrando los atributos y bondades del colegio } \\
\text { y su plan de estudio. }\end{array}$ & $\begin{array}{l}\text { Realizar programa de actualización sobre tecnologías de } \\
\text { información, comunicación y soluciones de software, } \\
\text { orientados al nivel estratégico de la organización y sobre, } \\
\text { con el fin de integrar a la empresa en la red de valor y ser } \\
\text { competitiva. }\end{array}$ \\
\hline & $\begin{array}{l}\text { Establecer relaciones gana-gana con los socios de } \\
\text { negocio aguas arriba. }\end{array}$ & Elaborar una política de atención al cliente. \\
\hline & $\begin{array}{l}\text { Formular planes operativos y tácticos para los pro- } \\
\text { cesos logísticos teniendo en cuenta la integración } \\
\text { con los socios de negocio. }\end{array}$ & $\begin{array}{l}\text { Elaborar estudios de Benchmarking, permitiendo la con- } \\
\text { solidación de procesos y de una red logística. }\end{array}$ \\
\hline
\end{tabular}

Fuente: Elaboración propia 
A continuación, se procede a describir las metas que se plantean para el logro de los proyectos estratégicos propuestos; se debe tener en cuenta que todas las metas u objetivos propuestos se deben realizar bajo enfoques de SCM:

\section{Organización administrativa y logística:}

- Definir el direccionamiento estratégico de la empresa en cuanto a la logística

- Definición de procesos y subprocesos de logística, teniendo en cuenta la integración con la red de valor.

- Definición de un manual de funciones en logística, con el fin de que los responsables de procesos logísticos tengan claro sus responsabilidades y el alcance de sus cargos.

- Formulación de planes tácticos y operativos para los procesos de logística en la empresa, teniendo en cuenta la integración a la red de valor.

- Estandarizar y certificar los procesos claves del negocio teniendo en cuenta las relaciones de integración con los socios de negocio.

- Formular programas sobre Resiliencia en Supply Chain, con el fin de tener claridad sobre los eventos adversos internos y externos que pudieran afectar el flujo de los procesos logísticos en la empresa.

\section{Relaciones con socios de negocio con enfo- que en SCM:}

-Establecer alianzas con los proveedores fundamentadas en relaciones de confianza, basados en protocolos de acuerdos de servicio (PSA) que busquen relaciones gana-gana.

- Fomentar relaciones C3 con los socios de negocio, es decir, relaciones coordinadas, cooperadas y colaborativas para el desarrollo de los procesos logísticos en la red de valor.

- Formular proyectos de asociatividad concebidos bajo enfoques de SCM con los socios de negocio aguas arriba.

\section{Infraestructura tecnológica:}

- Definir las necesidades tecnológicas de la empresa, teniendo en cuenta los procesos logísticos y la integración con la red de valor.

- Evaluar, seleccionar y adquirir los SI y TIC disponibles en el mercado y que se ajusten a las características de la empresa y le permita integrarse a la red de valor.

-Evaluar las competencias técnicas y profesionales en logística del personal administrativo y logístico de la empresa.

-Evaluar las competencias profesionales y postgraduales del personal de voluntarias de la empresa, con el fin de identificar apoyos futuros en cuanto a capacitaciones.

- Formular plan de capacitación en logística y SCM para el personal administrativo y operativo.

\section{Conclusiones}

De los resultados obtenidos, se puede vislumbrar el papel preponderante que cumple la logística al interior de las empresas y sus redes de valor. Ésta, debe considerarse como una actividad estratégica de las organizaciones, pues es clave para establecer o consolidar ventajas competitivas a través de la aplicación de las mejores prácticas generándole un valor agregado al cliente.

Del diagnóstico en competitividad en integración del supply chain management y logística, se puede concluir que deben realizarse cambios en la gestión logística de la empresa y la manera como está se integra a la red de valor. Se puede observar una empresa con una gestión organizacional vertical con falencias para migrar a otros modelos administrativos con enfoques en supply chain management; no existe una sección o coordinación logística que centre, controle e integre todos los procesos logísticos de la empresa. La integración con los socios de negocio es prácticamente inexistente. No se manejan relaciones de confianza basadas en el enfoque C3 (relaciones cooperadas, colaborativos y coordinadas), lo que se ha visto reflejado en la competitividad y en el servicio al cliente. 
Se hace necesario desarrollar estrategias conjuntas con los socios de negocio que permitan obtener mejoras continuas en la logística empresarial. Asimismo, se vislumbran falencias en cuanto al uso de tecnologías para el manejo de la gestión logística, lo que se considera también un punto negativo para facilitar la integración a la red de valor.

La caracterización en logística, así como el diagnostico en competitividad, dejan entrever una empresa que tiene desconocimiento de las ventajas competitivas de la gestión logística y de la red de valor. Esta se centra en la realización de actividades administrativas en el día a día (de manera tácita) tratando de solucionar los problemas que se presentan, ejecutando procesos que no están debidamente documentados. Sin embargo, se resalta el trabajo, de una u otra forma, interfuncional que realiza el personal administrativo y operativo de la empresa para sacar adelante los procesos logísticos, así como su compromiso y dedicación. Asimismo, los intentos por elaborar los procedimientos de las actividades claves del negocio que han tenido.

Estos proyectos estratégicos se han formulado con el fin de que la empresa pueda mejorar la gestión logística interna y está sea extendida hacia su red de valor, con una concientización y cultura plena y extensible del concepto de logística y supply chain management no solo en el ámbito empresarial, sino también en la red de valor; se fomenten alianzas estratégicas y relaciones gana-gana coordinadas, cooperadas y colaborativas con los socios de negocio potencializadas por el uso de SI y TIC actualizados y acordes con las capacidades de la empresa y los socios de negocio. Todo lo anterior, buscando el sostenimiento, ser más productiva y el desarrollo de la empresa en el mundo Competitivo.

De lo anterior, se evidencia la magnitud del impacto de la planeación estratégica logística en una empresa, planeación que deberá hacerse extendida a la red de valor si se quiere constituir en una ventaja competitiva. Con los proyectos estratégicos propuestos dentro de la planeación estratégica logística, se espera haber tocado los aspectos y las problemáticas más significativas que se deben atacar y controlar en la empresa con el fin de aportar y potencializar el logro de los objetivos corporativos.

\section{Discusión y futuras investigaciones}

Se recomienda la realización de futuros proyectos de investigación, que arrojen resultados que ayuden y permitan a la empresa virar de una organización con estructura vertical a una horizontal o extendida (con enfoque de SCM).

Asimismo, se plantea que la empresa busque la excelencia empresarial a través de la documentación e implementación de sistemas de gestión de la calidad que potencialicen el direccionamiento estratégico, táctico y operativo de la empresa.

Por otro lado, se exhorta a formular y desarrollar planes de actualización de las tecnologías de información y comunicación (TIC), que estén orientados a la parte estratégica y operativa de la empresa y que permitan potencializar las relaciones de integración con los socios de negocio. No se debe olvidar las fortalezas en SI que tienen los socios de negocio aguas arriba, las cuales, deben ser aprovechadas en el momento, como un primer acercamiento a la integración de la gestión logística.

Se propone promover y desarrollar planes de capacitación en logística y Administración de redes de valor, no solo desde adentro de la empresa sino también en cooperación y coordinación con los sectores externos afines a los intereses de la empresa y con los socios de negocio.

Es importante establecer el direccionamiento de la empresa, de tal forma, que para cada gerente que llegue cuando se realicen relevos de oficiales, haya un horizonte claro de las políticas, los objetivos estratégicos y los mecanismos existentes para lograr las metas establecidas en la planeación estratégica empresarial.

\section{Referencias bibliográficas}

Aldana, A. C. P. (2018). Propuesta de un plan estratégico logístico para una empresa de carácter social sin ánimo de lucro (Seccional Cali). Revista científica anfibios, 1(2), 60-68. 
Alvarán, J. C. Á. (2018). Logística: punto de inflexión del mercado moderno. Revista científica anfibios, 1(2), 21-27.

Balza-Franco, V., Paternina-Arboleda, C. D., Cantillo, V., Macea, L. F., \& Ramírez-Ríos, D. G. (2017). A collaborative supply chain model for non-for-profit networks based on cooperative game theory. International Journal of Logistics Systems and Management, 26(4), 475-496. https://doi.org/https://doi.org/10.1504/IJLSM.2017.082614

Bowersox, D., J., (1974). Logistical Management. New york: Macmillan Publishing Co.

Del Río Cortina, J., Velasco Alma Rocio, I., Mendoza Jimenez, W., Pérez Narváez, K., Castilla Pue1lo, C., Orozco Barrera, A., \& Herrera Ballesteros, W. (2009). Una Perspectiva De La Logística Desde la Academia. Cartagena de Indias

Lambert, D., Cooper M. (1998). Supply Chain Management implementations: Issues and Research opportunities. The international Journal of Logístics Management. 9

Lambert, D., García-Dastugue, S. \&Croxton, K. (2005). An evaluation of process-oriented supply chain management frameworks. Journal of Business Logistics, 26, (1), 25-51

Lamprea Roa, M \& Mendoza Perdomo, L. (2009). Plan estratégico y operativo de la empresa de familia, Ferretería del Meta ubicada en la ciudad de Villavicencio. (Trabajo de grado, Universidad de la Salle)

López Roa, Jessica L., Méndez Romero, Diego A., Molina Rincón, Julio C. (2013). Descripción de la cadena de abastecimiento en las mi pymes del sector autopartista en la ciudad de Bogotá D.C. (Trabajo de grado, Universidad de la Salle)

Restrepo de O., Luz Stella; Estrada Mejía, Sandra; Ballesteros S., Pedro Pablo; (2010). Planeación estratégica logística para un holding empresarial. Scientia et technica, abril, 16(44), 90-95, ISSN 0122-1701

Said C. Feres E., (2007). Modelo Referencial en logística. Documento de trabajo. Centro de investigaciones y asistencia técnica internación John F. Kennedy - CIATI. Bogotá D.C

Said C. Feres E., (2009). Supply Chain Management y logística: De cadenas a redes adaptativas. Documento de trabajo. Maestría en Gestión logística. Escuela Naval de cadetes Almirante Padilla. Cartagena D.T y $\mathrm{P}$

Said C. Feres E., Pinzón Hoyos, Fabiola, Rodríguez, Juan C., Narváez, Gladis. (2003). Competitividad en integración del supply chain y logística en la industrial astillera de Colombia

Sánchez Quintero, J. (2003). Estrategia integral para pymes visionarias. Revista Escuela de Administración de Negocios. Universidad EAN. No. 47 (enero - abril). Págs. 34 - 45. Colombia. ISSN: 0120-8160

Servera - Francés, D. (2010). Concepto y evolución de la función logística. Revista Innovar Journal Revista de Ciencias Administrativas y Sociales. 20(38), 217-234. ISSN electrónico 2248-6968. DOI 10.15446 